\title{
Awareness and Preferences for Health Care Chaplaincy Services Among US Adults
}

\author{
Geila Rajaee, MPH, MPA, MDiv, and Minal R. Patel, PhD, MPH
}

Purpose: Health care chaplains intervene on unmet religious/spiritual (R/S) needs in health care settings that are associated with poor outcomes. Little is known about demand for their services. The purpose of this study was to describe population-level awareness and perceptions of health care chaplains and preferences for their services.

Methods: Data came from a cross-sectional survey of a nationally representative sample of US adults $\geq 18$ years of age $(n=1020)$. Participants were asked about preferences for chaplain services, previous experience and awareness of chaplains, and level of importance on having $R / S$ needs and sources of meaning addressed.

Results: Mean age of the sample was 47.6. Although the majority were aware of chaplains (85\%), only $15 \%$ indicated they had previous experience with one. Adults who were unaware were younger (38 vs 49 years, $p<.001)$, male $(P=.007)$, non-white race/ethnicity $(p<.001)$, and had lower educational attainment $(P=.01)$. Seventy percent reported an interest in having $R / S$ or existential needs met in the context of health care.

Conclusions: The majority of the US population say they are aware of chaplains and desire their services, yet few report previous experience with them in health care. More behavioral interventions are needed to better connect patients to chaplains. ( $\mathrm{J}$ Am Board Fam Med 2021;34:368-374.)

Keywords: Behavioral Medicine, Chaplains, Cross-Sectional Studies, Delivery of Health Care, Hospital Chaplaincy Service, Patient-Centered Care, Spiritualism

\section{Introduction}

The integration of spiritual and/or religious care for patients has been highlighted as a meaningful way to impact patient care and aligns with models of care that focus on the whole person. ${ }^{1}$ Attention to spiritual needs within the health care context has been most concentrated in the context of palliative and end-of-life care, advanced cancer, and those facing serious illness. Fifty percent of patients in these

This article was externally peer reviewed.

Submitted 28 July 2020; revised 4 October 2020; accepted 6 October 2020.

From the Department of Health Behavior \& Health Education, University of Michigan, Ann Arbor.

Conflicts of interest: GR reports personal fees from United Healthcare, personal fees from Transforming Chaplaincy, and personal fees from the Association of Clinical Pastoral Education, outside the submitted work. MRP has no financial disclosures or conflicts to report.

Prior presentation: These data were presented at the Society of Behavioral Medicine Annual Meeting (2020) as a virtual poster presentation.

Corresponding author: Minal Patel, $\mathrm{PhD}, \mathrm{MPH}$, Department of Health Behavior and Health Education, University of Michigan School of Public Health, 1415 contexts indicate that they want to discuss their religious/spiritual (R/S) needs with their care team, ${ }^{1}$ $58 \%$ to $94 \%$ want their physicians to ask about their spiritual beliefs despite only a small percentage receiving any inquiry, ${ }^{2,3}$ and $18 \%$ to $53 \%$ of patients indicate some level of R/S distress. ${ }^{4-6}$ When the needs that result from $\mathrm{R} / \mathrm{S}$ distress are unmet in hospital settings, patients report more depressive symptoms and emotional distress, ${ }^{6-11}$ lower quality of life scores, ${ }^{10,12}$ increased anxiety, poorer physical wellbeing, ${ }^{9,13}$ and increased mortality. ${ }^{12}$

Nearly two thirds of all hospitals use chaplains to address R/S and existential needs of patients and their families, yet chaplains are underused. ${ }^{14-16} \mathrm{~A}$ chaplains is often identified as the care-team member who is responsible for meeting $\mathrm{R} / \mathrm{S}$ needs of patients. Chaplains also engage more holistically with patients and families by aligning patient values with actions in light of illness or injury and more broadly exploring

Washington Heights, 3810 SPH I, Ann Arbor, MI 48109 (E-mail: minalrp@umich.edu). 
existential concerns. ${ }^{17,18}$ Board-certified chaplains typically have graduate-level education, have completed an additional year or more of clinical training (known as clinical pastoral education), and maintain ongoing certification. ${ }^{16,19-21}$ Although many chaplains personally identify with a faith tradition or no faith tradition (eg, secular humanists), their training consists of additional education on psychological theories related to human development or organizational behavior; providing care that respects difference and diversity (eg, culture, ethnicity, gender, sexual orientation, and/or R/S practice); providing spiritual support that benefits the well-being of patients, families, and staff; and fostering collaborative relationships within the interdisciplinary team to enhance the patient experience. ${ }^{19,22}$ Board-certified chaplains have the capacity and flexibility to work with people from any or no faith background and integrate what is most important to patients into their care. Outside of the typical R/S needs, they provide a wide range of services to patients, families, and staff, including grief and loss care, conflict resolution, crisis intervention, and facilitation of communication, and they use a values-based approach in helping people make health care decisions. ${ }^{17,23}$

As an existing service available to everyone within the acute care setting, chaplaincy services have been associated with better patient experience ratings, ${ }^{24}$ decreased distress at end of life for surviving family members, ${ }^{25}$ and reducing distress with end-of-life decision-making ${ }^{26}$ and advance care planning. ${ }^{27}$ When $\mathrm{R} / \mathrm{S}$ needs are addressed, there is improved decisionmaking, ${ }^{28}$ decreased spending at end of life, ${ }^{29}$ lower in-hospital deaths and higher hospice enrollment, ${ }^{30}$ increased patient satisfaction measures, ${ }^{1}$ and improved health behaviors, coping, and social health. ${ }^{31}$

The existing literature on health care chaplains does not address the perceptions of US adults (as nonpatients) about the role of a health care chaplain in care settings. Gaps also remain around general knowledge regarding the full range of services that chaplains provide on the care team. Prior work has focused on the perspectives of other medical professionals (eg, physicians, nurses) ${ }^{32-35}$ or retrospective exploration of patient experiences with chaplains. ${ }^{36}$ There is also little known about preferences of US adults in seeing a chaplain while receiving health care services despite evidence that suggests that attending to the spiritual, existential, and/or religious needs of patients has a meaningful impact on health. ${ }^{31}$ The purpose of this article is to describe the population-level awareness of and perceptions of health care chaplains and preferences for services that they typically deliver among a nationally representative sample of US adults.

\section{Methods}

\section{Study Design, Data Sources, and Study Population}

Data came from a nationally representative US sample through an Ipsos Government \& Academic Omnibus (G\&A) panel. Ipsos is a private firm that conducts nationally representative surveys. Participants in the panel were surveyed about support services desired in the inpatient and outpatient practice setting as well as interest in seeing a chaplain. The G\&A survey panel uses address-based sampling with a probability approach to reach households with and without Internet access. Once panel members have been identified by Ipsos, an equal probability selection method is used for all general population surveys. The panel members selected to participate in a survey are provided an email notification inviting them to the survey with at least 1 reminder 3 days following the initial notification. For participants who do not have access to a computer, Ipsos provides resources for a survey response. A modest incentive is provided to panel participants. All participants of the panel are US adults ages $\geq 18$ respective to state laws and representative of the U.S adult population. Participants completed the survey administered by G\&A in December 2018. The study was approved by the University of Michigan Institutional Review Board.

Over the recruitment period, a total of 1864 people met inclusion criteria for participation. Of those who agreed to participate in the survey $(n=1030), 10$ participants were removed for not completing the survey. Our final sample size for this analysis was 1020 participants (response rate of 55.3\%). Design weights were calculated by G\&A using the US Census Bureau's American Community Survey. ${ }^{37}$ The calculated weights are scaled to the total sample size of eligible participants. ${ }^{37}$

\section{Measures}

Participants were asked to respond to questions related to chaplain services that could be provided in a routine (outpatient) medical appointment or while being admitted to the hospital and the level of importance that respondents place on having their religious, spiritual, and/or sources of meaning 
addressed. Additional questions included previous experiences with a chaplain and if respondents would be interested in seeing a chaplain in either setting (outpatient medical appointment and/or inpatient hospital stay). There was no explanation given regarding the term "chaplain" to ascertain participants' general response to the term. Standard demographic information was also collected.

\section{Desire for Chaplain Consults}

Our primary outcome was a desire for chaplain consults in health care settings. This was measured by asking participants if they would want to see a chaplain in either an outpatient appointment ("annual routine visit with your doctor, an outpatient medical procedure, or any routine medical treatment") or while being hospitalized ("Yes," "No," and "Unsure"). No definition of a chaplain was provided in either question.

\section{Awareness of and Previous Experience with Chaplains}

We measured the level of perceived awareness of chaplains by creating a composite variable that was inclusive of any time people indicated in the survey that they did not know what a chaplain is. This statement ("I do not know what a chaplain is") was provided as a response option along with "Yes," "No," and "Unsure." People who indicated they did not know what a chaplain was were identified as having lower awareness of chaplains, and those who indicated "Yes," "No," or "Unsure" were considered more aware. We also identified those with previous experience with a chaplain in a health care setting from this question. People who indicated that they had met a chaplain ("Yes") were compared with those who have not met a chaplain ("No") and those who could not remember if they did ("Unsure"). In our measure of awareness of chaplains, we included "Unsure" for people where they or their loved ones may have met with a chaplain and/or were unable to recall meeting a chaplain.

\section{Perceived Value of Chaplains}

Participants were asked to rate how important it would be to have their religious, spiritual, or meaning-based (existential) needs met while hospitalized using a 10 -point scale $(1=$ Not at all important, $10=$ Very important). Perceived value of chaplains was used as a continuous measure to indicate value or importance that people place on religious, spiritual, or meaning-based needs. For interpretative purposes, cutoffs were determined to ascertain the frequency between low ( 1 to 3 ), moderate (4 to 6 ), and high value (7 to 10 ).

\section{Preferences for Types of Services Offered}

Participants were asked for their preferences for the types of services often provided by chaplains, primed for either outpatient/routine care or inpatient/acute care (eg, exploring spiritual/religious concerns and exploring values as it relates to treatment decisions). Response options were "Yes," "No," and "Unsure" for each item.

\section{Statistical Analysis}

All analyses were completed using SAS (version 9.4) in 2019. Descriptive statistics, chi-squared, and $t$ test were computed to describe the demographic differences of people aware and unaware of what a chaplain is. Frequencies were used to describe specific types of services provided by chaplains in both the outpatient or inpatient setting as well as previous experience and perceived value of chaplains.

\section{Results}

\section{Sample Characteristics}

Table 1 presents the descriptive characteristics of the sample $(\mathrm{n}=1020)$. The mean age of participants was $47.6(\mathrm{SD}=17.3), 51 \%$ were female, and $64 \%$ reported being married or living with a partner. Sixty-three percent were non-Hispanic White, $12 \%$ non-Hispanic Black, 16\% Hispanic, and 8\% reported mixed/other race. Twenty-six percent of the sample reported an annual income of less than $\$ 39,999$, and $26 \%$ reported more than $\$ 125,000$. Thirty-eight percent reside in the southern region of the United States, $18 \%$ in the Northeast, $21 \%$ in the Midwest, and 24\% in the western region.

\section{Population Preferences for Types of Services Chaplains Provide by Outpatient and Inpatient Setting}

Table 2 shows participants' preferences in either the inpatient or outpatient setting for services typically provided by a chaplain. The most frequently cited preferred services of interest across settings were to "Discuss what is most important to you in the event of a life-threatening illness or injury" (55\% to 59\%) and "Explore your values as it relates to treatment decisions" (50\% to $55 \%$ ). Services most frequently cited that participants did not want 
Table 1. Demographic Characteristics of the Sample by Those Who Do and Do Not Know What a Chaplain Is

\begin{tabular}{|c|c|c|c|c|}
\hline & $\begin{array}{l}\text { Full Sample } \\
(\mathrm{n}=1020) \\
\end{array}$ & $\begin{array}{l}\text { Do Not Know What a Chaplain Is } \\
\qquad(\mathrm{n}=138)\end{array}$ & $\begin{array}{l}\text { Do Know What a Chaplain Is } \\
(\mathrm{n}=880)\end{array}$ & \\
\hline Characteristics & No. (\%) & No. (\%) & No. (\%) & $P$ Value \\
\hline Age, mean years* (SD) & $47.6(17.3)$ & $37.7(17)$ & $49.6(16.6)$ & $<.0001$ \\
\hline Sex $(\text { female }, \%)^{\star *}$ & $525(51)$ & $67(7)$ & $458(45)$ & .007 \\
\hline Race and ethnicity** & & & & $<.001$ \\
\hline Non-Hispanic White & $648(64)$ & $81(8)$ & $563(55)$ & \\
\hline Non-Hispanic Black & $121(12)$ & $16(2)$ & $105(10)$ & \\
\hline Hispanic & $165(16)$ & $40(4)$ & $125(12)$ & \\
\hline Other/mixed & $86(8)$ & $23(3)$ & $62(6)$ & \\
\hline Marital status** & & & & .001 \\
\hline Married Partner & $653(64)$ & $99(10)$ & $554(55)$ & \\
\hline Widowed & $41(4)$ & & $41(4)$ & \\
\hline Divorced/separated & $116(11)$ & $12(2)$ & $104(10)$ & \\
\hline Never married & $210(21)$ & $50(5)$ & $157(15)$ & \\
\hline Income status** & & & & .29 \\
\hline$<\$ 5,000-\$ 39,999$ & $267(26)$ & $49(5)$ & $219(22)$ & \\
\hline$\$ 40,000-\$ 74,999$ & $246(24)$ & $39(4)$ & $205(20)$ & \\
\hline$\$ 75,000-\$ 124,999$ & $244(24)$ & $30(3)$ & $214(21)$ & \\
\hline$>\$ 125,000$ & $263(26)$ & $42(4)$ & $220(22)$ & \\
\hline Education $^{* *}$ & & & & .01 \\
\hline Less than high school & $89(9)$ & $24(2)$ & $65(6)$ & \\
\hline High school & $313(31)$ & $50(5)$ & $263(26)$ & \\
\hline Some college & $288(28)$ & $36(4)$ & $249(24)$ & \\
\hline Bachelor's degree or higher & $330(32)$ & $50(35)$ & $279(27)$ & \\
\hline US region** & & & & .8 \\
\hline Northeast & $181(18)$ & $28(3)$ & $154(15)$ & \\
\hline Midwest & $212(21)$ & $34(3)$ & $177(17)$ & \\
\hline South & $385(38)$ & $56(5)$ & $325(32)$ & \\
\hline West & $242(23)$ & $42(4)$ & $199(20)$ & \\
\hline
\end{tabular}

National estimates based on complex survey design using mean or count. Statistical tests were completed using $t$ test* and $\chi^{2}$ tests**. $^{* *}$

$\mathrm{SD}$, standard deviation.

in both settings were to "Explore your spiritual and/or religious concerns" (66\% to 69\%), "Help find resources for spiritual coping" (62\% to 68\%), "Help you reflect on the meaning of your life and future hopes and goals" (61\% to 62\%), and "Help navigate interpersonal conflict" (60\% to $61 \%)$. Across all preferences in both the inpatient and outpatient settings, $12 \%$ to $19 \%$ remained unsure if they would or would not be interested in the types of services chaplains provide.

\section{Awareness, Previous Experience, and Perceived Value of Chaplains}

The majority of the sample (84\%) expressed some awareness of chaplains. Compared with the population that knows what a chaplain is, adults who did not know what a chaplain is were younger (37.7 vs 49.6 years, $P<.0001)$, were more likely to be male $(P=.007)$, a racial/ethnic minority $(P<.001)$, and have lower educational attainment $(P=.01)$. All participants who indicated their marital status as widowed knew what a chaplain is (Table 1). The majority of participants reported that they had not previously met with a chaplain (85\%) in a health care setting, and 4\% were unsure. Fifty-eight percent of the sample expressed moderate to high perceived value in the services that chaplains provide, while $42 \%$ indicated low perceived value.

\section{Discussion}

To our knowledge, this is the first study that has explored population-level preferences around 


\begin{tabular}{|c|c|c|c|c|c|c|}
\hline & \multicolumn{3}{|c|}{ Outpatient No. (\%) } & \multicolumn{3}{|c|}{ Inpatient No. (\%) } \\
\hline & Yes & Unsure & No & Yes & Unsure & No \\
\hline $\begin{array}{l}\text { Incorporate your faith and cultural traditions into your } \\
\text { care in a way that is personally meaningful }\end{array}$ & $271(27)$ & $166(16)$ & $577(57)$ & $314(32)$ & $151(15)$ & $541(54)$ \\
\hline Explore your spiritual and/or religious concerns & $170(17)$ & $140(14)$ & $701(69)$ & $206(21)$ & $135(13)$ & $663(66)$ \\
\hline $\begin{array}{l}\text { Help you stay connected to what you find most } \\
\text { meaningful in your life (such as relationships, important } \\
\text { communities and/or groups) }\end{array}$ & $297(29)$ & $166(16)$ & $549(54)$ & $339(34)$ & $142(14)$ & $520(52)$ \\
\hline $\begin{array}{l}\text { Help connect you to resources for personal strength and } \\
\text { resilience }\end{array}$ & $374(37)$ & $156(15)$ & $479(47)$ & $393(39)$ & $142(14)$ & $468(47)$ \\
\hline Help find resources for spiritual coping & $178(18)$ & $150(15)$ & $684(68)$ & $225(22)$ & $152(15)$ & $627(62)$ \\
\hline Explore your values as it relates to treatment decisions & $505(50)$ & $150(15)$ & $351(35)$ & $554(55)$ & $118(12)$ & $329(33)$ \\
\hline $\begin{array}{l}\text { Discuss what is most important to you in the event of a } \\
\text { life-threatening illness or injury }\end{array}$ & $557(55)$ & $134(13)$ & $322(32)$ & $573(59)$ & $118(12)$ & $314(31)$ \\
\hline $\begin{array}{l}\text { Help you reflect on the meaning of your life and future } \\
\text { hopes and goals }\end{array}$ & $225(22)$ & $157(16)$ & $629(62)$ & $242(24)$ & $151(15)$ & $609(61)$ \\
\hline Help navigate interpersonal conflict & $196(19)$ & $194(19)$ & $621(61)$ & $235(23)$ & $163(16)$ & $604(60)$ \\
\hline Help you with end-of-life planning & $338(34)$ & $184(18)$ & $487(48)$ & $415(41)$ & $166(16)$ & $424(42)$ \\
\hline
\end{tabular}

chaplaincy services in a nationally representative sample of US adults. We found that the majority of US adults say they are aware of chaplains, with specific groups having a greater awareness of chaplains (widowed persons, women). We also found that very few people have seen a chaplain in a health care setting, yet nearly $60 \%$ of people have an interest in R/S support. Fewer people also want obvious religious-focused services, but there is still significant interest in services specific to spiritual/ existential support. Our findings are consistent with other work that indicates that attention to spiritual needs is important to patients. ${ }^{36,38}$

We found that a significant proportion of the sample indicated that they were aware of chaplains, yet very few indicated that they have previously met with one. We did not ask participants in-depth questions about their awareness, which should be explored in a future study. There seems to be a disconnect between the experience of chaplains and awareness of them, given that so many indicate that they are aware of them and yet have never met one. In light of the number of people who indicate their religious, spiritual, and/or existential needs would be important to them or indicate that they would like services provided by a chaplain, there may be a disconnect between what people believe about chaplains and their actual role on the health care team. There are a number of other possibilities, including the mean age of our sample skewing younger (47.6) compared with those often hospitalized, ${ }^{39}$ which may give them fewer opportunities to meet with a chaplain. Chaplains may also not have done an adequate job communicating their role, and/or the existing infrastructure to connect patients to chaplains is ineffectual. Last, people may have perceptions around who chaplains are that may be misaligned with their actual role. The assumptions that people make about what a chaplain is could influence their desire to have one consulted. Other work has shown that understanding of the training and role/function of a chaplain indicated a greater likelihood of referral among other health care professionals. ${ }^{33,35}$

There seems to be a substantial number of patients who would like to have their R/S or existential needs met while receiving medical care, and yet when asked about specific services desired in either the outpatient or inpatient setting, the least desired services related directly to religious needs or resources. This aligns with the changing dynamics of religion in the United States, with the rise of the nonreligious ("nones"), ${ }^{33-35}$ and highlights the need for chaplains to continue to develop skills for exploring existential needs without a religious framework. It also fills an important gap in the literature when it comes to better understanding what types of services patients receive or want to receive that chaplains provide. This finding points to an opportunity to refine patient screening protocols for chaplaincy services so that screening can better match the types of services people may be looking for. 
More participants indicated a desire to receive support for exploring what is most important in the event of a life-threatening illness or injury and values related to treatment decisions. Chaplains are those who are trained and certified on the care team to address these types of existential concerns. The language and approach that chaplains use is driven by the patient's values and language. This allows for conversations to occur about treatment decisions and medical adherence that helps support and clarify communication with the care team.

There are limitations in this study that should be noted. First, we did not give a definition of what a chaplain is within the survey, nor did we ask participants for their definition of a chaplain because our intent was to have them respond to the term "chaplain." Second, we were unable to ask about participants' engagement or experience with a faith community, if they identify themselves as nonreligious, and previous general experience with hospitals and health care. Our survey question on previous experience also limited the experience people may have had with a chaplain to a hospitalization. Participants may have had experiences with chaplains in outpatient cancer centers or other settings.

Despite these limitations, our findings have important implications for practice and research. A population-level demand exists around having R/S or existential needs met in health care settings. Many conversations that occur in the health care context are often focused on tasks that do not take into consideration patient or family-specific values as they relates to decisions. Our findings show that the role of chaplains on an interdisciplinary care team could be better clarified, and new models need to be considered to better address patients' spirituality and personal values within the context of health care. Aligning patients' values with their health care decisions may lead to improved outcomes as well as reduce the burden of the stressful decision-making that often occurs in the health care context.

The need to have patients explore values and existential concerns in the face of a life-threatening illness or injury needs to continue to move to the forefront of chaplain activities. As more people in the United States indicate no formal religious affiliation, it will become increasingly important to highlight the role of chaplains as care-team members who help support patients no matter if they do or do not align with a particular faith tradition. More in-depth research is needed to better understand peoples' awareness of chaplains to address areas of potential misalignment as well as more behavioral interventions that support the uptake of chaplains in health care settings.

Unmet R/S and existential needs within health care lead to gaps in holistic, patient-centered care due to our lack of understanding of people's preferences for support. This study identified that very few people have any actual experience with a chaplain despite indicating awareness of them. People are interested in addressing their existential concerns (eg, what is most important, valued) in a range of health care contexts, which further highlights the importance of having these types of conversations with the care team. Chaplains are a natural fit because they are trained and certified for this type of role. Additional research is warranted to understand people's awareness of chaplains and more behavioral interventions to improve chaplain referrals in health care settings to reduce the number of unmet R/S and existential needs.

To see this article online, please go to: http://jabfm.org/content/ 34/2/368.full.

\section{References}

1. Williams JA, Meltzer D, Arora V, Chung G, Curlin FA. Attention to inpatients' religious and spiritual concerns: predictors and association with patient satisfaction. J Gen Intern Med 2011;26: 1265-71.

2. Ehman JW, Ott BB, Short TH, Ciampa RC, HansenFlaschen J. Do patients want physicans to inquire about their spiritual or religious beliefs if they become gravely ill? Arch Intern Med 1999;159:1803-6.

3. Astrow AB, Wexler A, Texeira K, He M, Sulmasy DP. Is failure to meet spiritual needs associated with cancer patients' perceptions of quality of care and their satisfaction with care? J Clin Oncol 2007;25:5753-7.

4. Thune-Boyle IC, Stygall J, Keshtgar MR, Davidson TI, Newman SP. Religious coping strategies in patients diagnosed with breast cancer in the UK. Psychooncology 2011;20:771-82.

5. King SDW, Fitchett G, Berry DL. Screening for religious/spiritual struggle in blood and marrow transplant patients. Support Care Cancer 2013;21:993-1001.

6. Velosa T, Caldeira S, Capelas ML. Depression and spiritual distress in adult palliative patients: a crosssectional study. Religions 2017;8:156.

7. Pargament KI, Koenig HG, Tarakeshwar N, Hahn J. Religious coping methods as predictors of psychological, physical and spiritual outcomes among medically ill elderly patients: a two-year longitudinal study. J Health Psychol 2004;9:713-30. 
8. Delgado-Guay MO, Hui D, Parsons HA, et al. Spirituality, religiosity, and spiritual pain in advanced cancer patients. Journal Pain Symptom Management 2011;41:986-94.

9. Hills J, Paice JA, Cameron JR, Shott S. Spirituality and distress in palliative care consultation. J Palliat Med 2005;8:782-8.

10. Manning-Walsh J. Spiritual struggle: effect on quality of life and life satisfaction in women with breast cancer. J Holist Nurs 2005;23:120-40.; discussion 141-4.

11. Monod S, Martin E, Spencer B, Rochat E, Bula C. Validation of the Spiritual Distress Assessment Tool in older hospitalized patients. BMC Geriatr 2012;12:13.

12. Pargament KI, Koenig HG, Tarakeshwar N, Hahn J. Religious struggle as a predictor of mortality among medically ill elderly patients: a 2-year longitudinal study. Arch Intern Med 2001;161:1881-5.

13. Siddall PJ, McIndoe L, Austin P, Wrigley PJ. The impact of pain on spiritual well-being in people with a spinal cord injury. Spinal Cord 2017;55:105-11.

14. Cadge W, Freese J, Christakis NA. The provision of hospital chaplaincy in the United States: a national overview. South Med J 2008;101:626-30.

15. Cadge W. Paging God: religion in the halls of medicine. Chicago: University of Chicago Press; 2012.

16. Cadge $W$, Fitchett $G$, Haythorn $T$, et al. Training healthcare chaplains: yesterday, today and tomorrow. J Pastoral Care Counsel 2019;73:211-21.

17. Timmins F, Caldeira S, Murphy M, et al. The role of the healthcare chaplain: a literature review. J Health Care Chaplain 2017;1-20.

18. Cadge $W$. Healthcare chaplaincy as a companion profession: historical developments. J Health Care Chaplain 2019;25:45-60.

19. Board of Chaplaincy Inc. BCCI certification. 2020. Available from: https://bcci.professionalchaplains. org/content.asp?pl=25\&contentid=25.

20. Association of Clinical Pastoral Education. About ACPE. 2020. Available from: https://acpe.edu/aboutacpe.

21. Association of Professional Chaplains. Standards of practice for professional chaplains. 2020. Available from: https://www.professionalchaplains.org/content. asp?pl=198\&sl=198\& contentid=200.

22. Association of Clinical Pastoral Education. ACPE manuals. 2020. Available from: https://www.manula. com/manuals/acpe/acpe-manuals/2016/en/topic/coverpage.

23. Association of Professional Chaplains, et al. Professional chaplaincy: its role and importance in healthcare. J Pastoral Care 2001;55:81-97.

24. Marin DB, Sharma V, Sosunov E, Egorova N, Goldstein R, Handzo GF. Relationship between chaplain visits and patient satisfaction. J Health Care Chaplain 2015;21:14-24.
25. Johnson JR, Engelberg RA, Nielsen EL, et al. The association of spiritual care providers' activities with family members' satisfaction with care after a death in the ICU*. Crit Care Med 2014;42:1991-2000.

26. Steinhauser KE, Voils CI, Clipp EC, Bosworth $\mathrm{HB}$, Christakis NA, Tulsky JA. "Are you at peace?": one item to probe spiritual concerns at the end of life. Arch Intern Med 2006;166:101-5.

27. Lee AC, McGinness CE, Levine S, O'Mahony S, Fitchett G. Using chaplains to facilitate advance care planning in medical practice. JAMA Intern Med 2018;178:708.

28. Silvestri GA, Knittig S, Zoller JS, Nietert PJ. Importance of faith on medical decisions regarding cancer care. JCO 2003;21:1379-82.

29. Balboni T, Balboni M, Paulk ME, et al. Support of cancer patients' spiritual needs and associations with medical care costs at the end of life. Cancer 2011;117:5383-91.

30. Flannelly KJ, Emanuel LL, Handzo GF, Galek K, Silton NR, Carlson M. A national study of chaplaincy services and end-of-life outcomes. BMC Palliat Care 2012;11:10.

31. Salsman JM, Fitchett G, Merluzzi TV, Sherman AC, Park CL. Religion, spirituality, and health outcomes in cancer: a case for a meta-analytic investigation. Cancer 2015;121:3754-9.

32. Kyounghae K, Bauck A, Monroe A, Mallory M, Aslakson R. Critical care nurses' perceptions of and experiences with chaplains. J Hospice Palliative Nursing 2017;19:41-8.

33. Fitchett G, Rasinski $\mathrm{K}$, Cadge $W$, Curlin FA. Physicians' experience and satisfaction with chaplains: a national survey. Arch Intern Med 2009;169:1808-10.

34. Harr C, Openshaw L, Moore B. Interdisciplinary relationships between chaplains and social workers in health care settings. J Health Care Chaplain 2009;16:13-23.

35. King SD, Dimmers MA, Langer S, Murphy PE. Doctors' attentiveness to the spirituality/religion of their patients in pediatric and oncology settings in the Northwest USA. J Health Care Chaplain 2013;19:140-64.

36. Cunningham CJL, Panda M, Lambert J, Daniel G, DeMars K. Perceptions of chaplains' value and impact within hospital care teams. J Relig Health 2017;56:1231-47.

37. Thomas RK. Documentation for human subjects review committees. Ipsos; 2017.

38. Piderman KM, Marek DV, Jenkins SM, et al. Predicting patients' expectations of hospital chaplains: a multisite survey. Mayo Clin Proc 2010;85:1002-10.

39. Lucas JW, Benson V. Tables of summary health statistics for the U.S. population: 2018 National Health Interview Survey. 2019. 